\title{
Estimating activity-specific energy expenditure in a teleost fish, using accelerometer loggers
}

\author{
Serena Wright ${ }^{1,2, *}$, Julian D. Metcalfe ${ }^{1}$, Stuart Hetherington $^{1}$, Rory Wilson ${ }^{2}$ \\ ${ }^{1}$ Centre for Environment, Fisheries and Aquaculture Science, Pakefield Road, Lowestoft NR33 0HT, UK \\ ${ }^{2}$ Swansea University, Singleton Park, Swansea SA2 8PP, UK
}

\begin{abstract}
The ability to define and quantify the behaviour and energetic costs of different activities is fundamental to a full understanding of fish ecology and movement, but monitoring activity and measuring energy expenditure in fish in the field is problematic. New telemetry methods using data loggers that incorporate tri-axial accelerometers promise to provide a method for simultaneously recording the behaviour and activity-specific energy use in both the laboratory and field. Using electronic data loggers equipped with tri-axial accelerometers we have measured dynamic body acceleration (DBA) during aerobic exercise in European sea bass Dicentrarchus labrax whilst swimming in a swim-tunnel respirometer at ambient water temperatures of between 5.5 and $17.5^{\circ} \mathrm{C}$. For all individuals, dynamic body acceleration (both vectorial dynamic body acceleration [VeDBA] and overall dynamic body acceleration [ODBA]) scaled linearly with oxygen consumption and as a function of ambient temperature. When the 2 DBA metrics were compared, VeDBA was not significantly different from ODBA, though the value for Akaike's information criterion was lower for VeDBA (indicating a better fit for the VeDBA model). In this paper, we provide further evidence to support the use of acceleration as a means to quantify the activity-specific energetic costs of swimming in teleosts and highlight some of the problems associated with monitoring the activity and metabolic rate of fish in restricted laboratory conditions.
\end{abstract}

KEY WORDS: Acceleration · Fish · Energetics · Temperature $\cdot$ Respirometry Resale or republication not permitted without written consent of the publisher

\section{INTRODUCTION}

It has been proposed that metabolic rate can be considered a 'universal currency' in animal biology and ecology, providing an objective measure that can be used in attributing 'cost' to different activities and to assess what animals do to achieve energetically optimal behaviour (Brown et al. 2004, Shepard et al. 2009). Trade-offs between the cost and benefit of specific behaviours govern the success and survival of animals through natural selection. For example, for many species of fish the choice of being active or inactive at different times of the day will affect both feeding success (Bestley et al. 2008, Murphy et al. 2011) and the risk of predation (Stuart-Smith et al. 2007, Béguer-Pon et al. 2012). Measuring the energy turnover and ways in which energy is allocated to specific activities is therefore of central importance in our understanding of behavioural and physiological ecology.

Accurate estimates of metabolic rates can be made, relatively easily, in the laboratory, either directly by measuring heat output (calorimetry) (Walsberg \& Hoffman 2005, Pakkasmaa et al. 2006, Penttinen \& Kukkonen 2006) or indirectly by measuring oxygen consumption $M_{\mathrm{O}_{2}}$ (Clarke \& Johnston 1999). However, measuring field metabolic rate (FMR) is more problematic, especially for aquatic animals like fish. Presently, methods used to estimate FMR involve the indirect measurement of oxygen consumption, for which approaches include the use of electromyogram (EMG) telemetry (Hinch \& Rand 1998, Cooke et 
al. 2004), doubly labelled water (DLW) (e.g. Shaffer 2011), or records of heart rate $\left(f_{H}\right)$ (e.g. Gilman \& Wells 1993). EMG telemetry involves measuring bioelectrical voltage changes in the muscle of the subject and has provided great insights into the activity and behaviour of free-ranging animals, including fish (Hinch \& Rand 1998). DLW measures the subject's carbon dioxide production by monitoring relative changes in stable isotopes of oxygen and hydrogen (Speakman 1998). DLW can be used for air breathers, including mammals (Nagy 2005), reptiles (Bennett \& Nagy 1977) and birds (Masman et al. 1988, Shaffer et al. 2001, Mullers et al. 2009), but not for fish, because the high water flux across the gills and the low metabolic rate result in only slight changes in the divergence of isotope concentrations (Speakman 1997). In contrast, $f_{H}$ has been shown to provide a reasonably useful estimate of metabolic rate in large ( $>1 \mathrm{~kg})$ teleosts (Clark et al. 2005, Casselman et al. 2012), although limitations include high equipment costs, poor reliability (Butler et al. 2004) and variable relationships between $f_{H}$ and oxygen consumption (Thorarensen et al. 2005, Iversen et al. 2010). For example, 'frequency modulators' (like sea bass Dicentrarchus labrax) are able to regulate their cardiac output during exercise and digestion, causing differences in the scaling of $f_{H}$ with oxygen consumption (Iversen et al. 2010). Both the $f_{H}$ and DLW methods involve uncertainties; so, for fish, these methods do not fully provide behavioural and physiological ecologists with comprehensive tools for the study of FMR.

Movement is 1 of the 4 main bodily functions which incur energetic costs in ectotherms including fish, the others being basal metabolic rate (BMR) (Frappell \& Butler 2004), temperature-dependent energy expenditure (Beamish \& Trippel 1990) and specific dynamic action (SDA) (McCue 2006). These latter 3 are perhaps most easily modelled since estimates are accessible via allometric relationships, and they vary less in time and space than do movement-associated costs (cf. Claireaux et al. 2006, Fitzgibbon et al. 2007, Jordan \& Steffensen 2007). Movement-induced energetic expenditure is governed by muscle contractions and is typified by variable acceleration in the body (Gleiss et al. 2010), so records of the (3-dimensional) acceleration of fish should provide a useful proxy for activity-specific energy expenditure. Indeed, based on this, recent studies have already correlated dynamic body acceleration (DBA - derived from tri-axial acceleration measurements) with oxygen consumption for a range of terrestrial and aquatic species, including cane toads (Halsey \& White 2010), cor- morants (Wilson et al. 2006) and hammerhead sharks (Gleiss et al. 2010). Bi-axial acceleration (Clark et al. 2010) and acoustically transmitted acceleration (Murchie et al. 2011, Wilson et al. 2013) have also provided some exciting insights into fish behaviour and physiology. However, more studies are required to improve methodologies in this field of research, with issues arising from the complex interpretation of raw acceleration.

In this study, we have attempted to identify how DBA scales with activity and oxygen consumption at different temperatures for a teleost fish, the European sea bass Dicentrarchus labrax, in order to establish the extent to which DBA may provide a useful proxy for active metabolic rate (metabolism induced by movement of the body) as it has been shown for other animals. The effects of tagging and scaling of DBA derived using different data-processing methods are also explored and compared for future studies.

\section{MATERIALS AND METHODS}

All experiments were regulated by the UK Animals (Scientific Procedures) Act 1986 and carried out under the authority of UK Home Office project licence PPL 80/2434, having been approved by Cefas' local ethical review process.

\section{Approach}

To establish and quantify the relationship between DBA and metabolic rate in European sea bass Dicentrarchus labrax, we simultaneously recorded DBA and mass-specific oxygen consumption $\left(M_{\mathrm{O}_{2}}\right)$. DBA was recorded using internally implanted data storage loggers equipped with 3-dimensional accelerometers, while oxygen consumption was measured in a swim-tunnel respirometer at rest and during steadystate, fully aerobic swimming, at speeds between 0.3 and 1.8 body lengths (BL) $\mathrm{s}^{-1}$ and at water temperatures ranging from 5.5 to $17.5^{\circ} \mathrm{C}$. During swim trials, several (usually 3) measurements of $M_{\mathrm{O}_{2}}$ were recorded at each water speed, depending on the swimming capabilities of each fish. Bass $(n=9)$ were obtained from Sea Life Centre at Great Yarmouth, Norfolk, UK, and held at the Cefas Laboratory, Lowestoft, in a tank supplied with aerated seawater at ambient temperatures $\left(5.2\right.$ to $17.8^{\circ} \mathrm{C}$ ). Total fish lengths ranged from 45.1 to $55.0 \mathrm{~cm}$, with total weights from 1100 to $2200 \mathrm{~g}$. Bass become easily agitated when attempting to transfer them between 
tanks; thus, to acclimatise them to the presence of the net and to reduce the stress when moving them from the holding aquaria to the swim-tunnel, we exposed them to a daily 'net challenge' by placing the net in their tank for 2 min each day, after which they were fed a diet of sand eel or sardine (ad libitum).

\section{Experimental setup}

Respirometry

Oxygen consumption was measured in a Brett-type swim tunnel respirometer (Brett 1965) using intermittent flow respirometry as described by Melzner et al. (2009). Briefly, the respirometer (swim chamber section of $25 \times 25 \times 87 \mathrm{~cm}$ ) was submerged in an outer tank, which measured $232 \times 95 \times 70 \mathrm{~cm}$ having a total water capacity of 187 l (Loligo Systems, ApS). The outer tank served as a source of aerated water used for flushing (flush pump, Eheim, $201 \mathrm{~min}^{-1}$ ) the respirometer (swim chamber) after each 'closed' measuring phase. Water quality in the outer tank was maintained by providing an inflow (10 $\left.1 \mathrm{~min}^{-1}\right)$ of fresh seawater. The water in the outer tank was kept fully aerated, and temperature was maintained using a temperature regulator (Loligo Systems).

Prior to each experiment, water velocities in the swim chamber were measured using a flow meter (HFA, Höntzsch) to calibrate the water speed control. Each swim trial was broken down into 'measurement', 'flush' and 'wait' phases. During the measurement phase, the oxygen tension of the water in the swim chamber was recorded using a galvanic oxygen electrode, while the swim chamber was completely closed from the outer tank. Oxygen consumption was calculated (see next paragraph) from the rate of decrease in oxygen tension. Subsequently, the swim chamber was flushed with aerated seawater from the outer tank to replenish oxygen levels (flush phase), and then a 'wait' phase enabled the oxygen levels to stabilise before the next measurement phase.

During swim trials, chamber flushing and the recirculation valve were controlled through an interface (DAQPAC-G1X, Loligo Systems) connected to a PC running AutoResp ${ }^{\mathrm{TM}}$ software (Version 1.6, Loligo Systems). Oxygen tension within the swim chamber was measured using a mini-DO galvanic cell oxygen probe suspended into the water current of the respirometer, which was connected to the DAQ interface, and oxygen saturation data was calculated using AutoResp ${ }^{\mathrm{TM}}$. To encourage the fish to maintain position toward the front of the swim chamber, a visual cue for orientation (Griffiths \& Alderdice 1972) was created using strips of black electrical tape spaced $1 \mathrm{~cm}$ apart, fixed vertically to the outer wall at the front of the chamber. After each experiment and after the fish had been removed from the swim chamber, oxygen saturation was monitored for a further $6 \mathrm{~h}$ to measure any oxygen consumption resulting from bacterial contamination.

To identify whether tagging had any effect on the oxygen consumption, swim trials were conducted on fish both before and after logger implantation.

\section{Accelerometer data-loggers}

Acceleration was recorded using G6a electronic data loggers (Cefas Technology; dimensions: $40 \mathrm{~mm}$ $\times 28 \mathrm{~mm} \times 16.3 \mathrm{~mm}, 18.5 \mathrm{~g}$ in air, $6.7 \mathrm{~g}$ in seawater) Loggers were pre-programmed to record acceleration data at $20 \mathrm{~Hz}$ and temperature once a minute for specific periods between the end of the surgical recovery (18 June 2011 or 16 February 2012) and the end of the study (20 September 2011 or 10 September 2012). The logger recorded raw acceleration in 3 planes of motion (Fig. 1), the $X$ (dorso-ventral: heave), $Y$ (side to side: sway) and $Z$ (anterior-posterior: surge). To maximise logger life, the data logging regime was designed to record principally during the swim trials. However, to compare the swimming activity of fish during swim trials with their spontaneous swimming activity, a number of additional recording periods were included in the data logging regime to allow data to be gathered during periods when the fish were swimming with conspecifics in their holding tank.

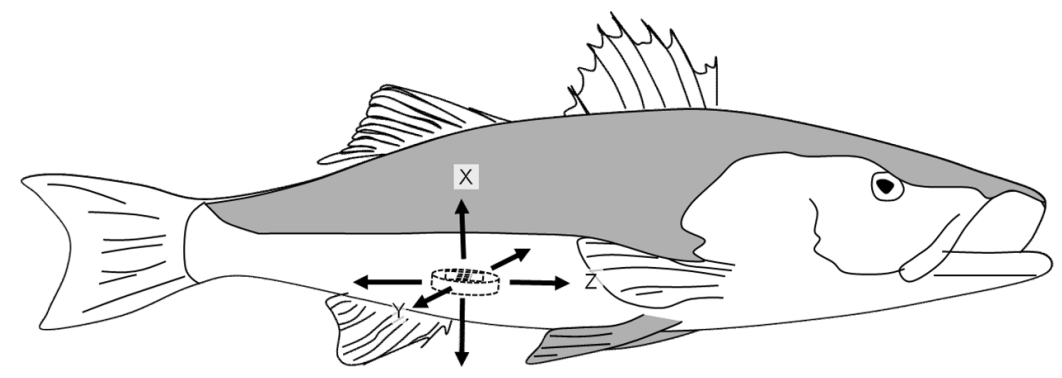

Fig. 1. Dicentrarchus labrax. Schematic diagram of a European sea bass internally implanted with a Cefas G6a data-storage tag. Arrows indicate the $(X)$ heave, $(Y)$ sway and $(Z)$ surge axes of acceleration recorded by the logger 


\section{Surgical implantation}

Loggers were implanted surgically into the peritoneum of the fish. Prior to surgery, fish were anaesthetised by immersion in seawater containing 2phenoxyethanol $\left(4 \mathrm{ml} \mathrm{l}^{-1}\right)$ for 3 to $5 \mathrm{~min}$. As fish lost equilibrium and opercula beat slowed, fish were measured and weighed. Fish were then placed on an operating table and held immobile in a sponge block. During surgery the gills were continuously irrigated with aerated seawater containing a maintenance dose $\left(2 \mathrm{ml} \mathrm{l}^{-1}\right)$ of anaesthetic (as above). A $3 \mathrm{~cm}$ midline ventral incision was made through the skin and muscle $4 \mathrm{~cm}$ anterior to the cloaca. The sterilised logger was then inserted into the peritoneal cavity and was sutured to the peritoneal wall to prevent it from moving within the peritoneum during the study and to decrease the risk of the logger being expelled through the incision wound (cf. Moore et al. 1990). The incision was closed with 2 or 3 interrupted sutures, and the wound was dressed with antibiotic powder (Vetremox antibiotic powder with an Orahesive mix [50:50]). Fish were then moved to their holding tank and held in a stream of fresh, aerated seawater until they regained equilibrium and strong opercular movements had resumed. The surgical procedure, from initial anaesthesia to final incision closure, took no more than $17 \mathrm{~min}$. Fish were allowed a minimum of $4 \mathrm{wk}$ to recover and to allow the data logger to become encapsulated (and therefore stabilised) within the body cavity, before swim trials were conducted.

\section{Swim trials}

Temperature effects the metabolism of ectothermic teleosts like sea bass (e.g. Claireaux et al. 2006) so our study was carried out at ambient seawater temperatures between June and September in 2011 (13 to $14^{\circ} \mathrm{C}$ ) and then between February and September in $2012\left(5\right.$ to $18^{\circ} \mathrm{C}$ ) to encompass a range of seasonal water temperatures between 5 and $18^{\circ} \mathrm{C}$. Although the plan was that each fish would be allowed to swim during the summer and winter trials, 3 fish expelled their data loggers before the end of the study (cf. Moore et al. 1990). Consequently, only data from the remaining fish were used for further swim trials; resulting in fewer fish in certain temperature groups (Table 1).
To remove any effects of specific dynamic action on oxygen consumption after feeding (Axelsson et al. 2002, Dupont-Prinet et al. 2009), fish were fasted for $72 \mathrm{~h}$ prior to swim trials. They were then measured, weighed, placed in the swim tunnel and allowed $16 \mathrm{~h}$ to recover from the oxygen debt accumulated during capture and transfer (Schurmann \& Steffensen 1997, Melzner et al. 2009). During acclimation, water speed was held constant at between 0.3 and $0.4 \mathrm{BL} \mathrm{s}^{-1}$. At these low water speeds the fish were able to get out of the flow and remain stationary.

Except when oxygen consumption was being measured, the swim chamber was flushed continuously to ensure the water was fully aerated. Oxygen consumption, either at rest or during swimming, was measured by turning the flush pump off, thereby sealing the swim chamber. Oxygen tension then decreased as the fish consumed the oxygen. Oxygen tension was allowed to decrease until saturation reached $\sim 90 \%$, a period of about $10 \mathrm{~min}$, before the flush pump restarted, restoring the oxygen tension of the water in the swim chamber back to full air saturation, again after a period of about 10 min. Oxygen consumption was calculated from the rate of decline in oxygen tension, the volume of the swim chamber and the solubility of oxygen in seawater at the experimental temperature (cf. Schurmann \& Steffensen 1997, Lee et al. 2003). Values for $M_{\mathrm{O}_{2}}$ in $\mathrm{mg} \mathrm{O} \mathrm{O}_{2} \mathrm{~kg}^{-1} \mathrm{~h}^{-1}$ were therefore recorded every 10 to 25 min depending on the duration of the flush cycles and represent the integrated oxygen consumption over a single measurement phase. $M_{\mathrm{O}_{2}}$ values were then converted from milligrams of $\mathrm{O}_{2}$ per kilogram per hour to micromoles of $\mathrm{O}_{2}$ per kilogram per hour before further processing. During swim trials, several (usually 3) measurements of $M_{\mathrm{O}_{2}}$ (i.e. over several flush cycles) were recorded at each water speed. Mean DBA (as both ODBA and VeDBA, see Eqs. 2 \& 3) values were calculated from the raw logger data for the corresponding oxygen consumption measurement periods.

Table 1. Dicentrarchus labrax. Experimental temperature groups, including the number of fish (n), the individuals (Fish ID) and the fish characteristics for each group

\begin{tabular}{|lccccc|}
\hline $\begin{array}{l}\text { Temp. } \\
\text { group }\end{array}$ & $\mathrm{n}$ & $\begin{array}{c}\text { Temperature } \\
\left(\mathrm{mean} \pm \mathrm{SD}^{\circ} \mathrm{C}\right)\end{array}$ & Fish ID & $\begin{array}{c}\text { Total length } \\
(\text { mean } \pm \mathrm{SD} ; \mathrm{cm})\end{array}$ & $\begin{array}{c}\text { Weight } \\
(\text { mean } \pm \mathrm{SD} ; \mathrm{g})\end{array}$ \\
\hline 6 & 4 & $6.05 \pm 0.32$ & $4,6,8,9$ & $52.42 \pm 2.2$ & $2435 \pm 195$ \\
7 & 1 & $7.27 \pm 0.13$ & 7 & $55.00 \pm 0.0$ & $2200 \pm 0$ \\
8 & 3 & $8.06 \pm 0.35$ & $5,7,8$ & $52.22 \pm 1.5$ & $1667 \pm 380$ \\
13 & 2 & $12.68 \pm 0.03$ & 1,3 & $49.91 \pm 3.8$ & $2025 \pm 692$ \\
14 & 3 & $13.71 \pm 0.12$ & $1,2,3$ & $50.87 \pm 3.2$ & $2145 \pm 587$ \\
17 & 3 & $17.27 \pm 0.16$ & $7,8,9$ & $52.13 \pm 2.1$ & $2749 \pm 32$ \\
\hline
\end{tabular}


Once acclimated to the swim chamber, swim trials were conducted during daylight hours between 09:00 and 17:00 $\mathrm{h}$ each day, to reduce any diurnal effects on metabolism (Lefrançois et al. 2001, Page et al. 2011). During trials, oxygen consumption was measured for a period of $10 \mathrm{~min}$ at a range of speeds up to the point where the fish would not hold station for the duration of the trial. Starting from rest, water speed was increased in steps of $0.125 \mathrm{BL} \mathrm{s}^{-1}$. If a fish was unable to hold station during a trial, the water speed was decreased briefly to enable the fish to regain position, before a further attempt at the failed speed was initiated. To ensure that oxygen consumption values were representative of set swimming speeds, data were only used from periods when the fish was holding station and swimming steadily (Grøttum \& Sigholt 1998, Ohlberger et al. 2007, Gleiss et al. 2010).

The presence of the fish within the swim chamber can cause a 'solid blocking effect', whereby the water speed increases as it flows past the fish (Bell \& Terhune 1970). If the cross-sectional area of the fish exceeded $10 \%$ of the cross-sectional area of the chamber, water speeds were corrected to account for this effect.

At the end of the experiment fish were humanely killed. Subsequently, but prior to its removal, the logger was calibrated in situ by slowly rotating the fish through $360^{\circ}$ in each of the 3 axes of acceleration. This allowed correction of the acceleration values where the logger was not aligned precisely with respect to the vertical. The final length, weight and sex of the fish were then measured, and the gills were checked for ecto-parasites which may have affected oxygen consumption (Powell et al. 2005), but no ecto-parasites were found on any of the fish, so all results were used in the following data analysis.

\section{Data analysis}

$M_{\mathrm{O}_{2}}$ was calculated from raw oxygen consumption values to account for size differences between test individuals (Fonds et al. 1992, Clarke \& Johnston 1999, Sloman et al. 2006) such that:

$$
M_{\mathrm{O}_{2}}=V \times\left(\frac{\delta p \mathrm{O}_{2}}{\delta t}\right) \times \alpha M^{-1}
$$

where $V$ is the volume of the swim tunnel, $\alpha$ is the oxygen solubility, $\mathrm{pO}_{2}$ is thepartial pressure of oxygen, $t$ is time and $M$ is the wet weight of the fish. $M_{\mathrm{O}_{2}}$ values were standardised to $800 \mathrm{~g}$ using an allometric scaling exponent of 0.8 (Fry 1971, Edwards et al. 1972).
To compare DBA at different levels of oxygen consumption both ODBA and VeDBA were derived from the acceleration data. ODBA is calculated by summing the dynamic acceleration values of the fish, and has been shown to be a marginally better proxy for oxygen consumption for a range of species including humans (Qasem et al. 2012). However, in situations where the orientation of the device is not necessarily aligned precisely with respect to the vertical, VeDBA (the vectorial sum of dynamic acceleration values) may be a better proxy (Qasem et al. 2012); though no studies to date have compared ODBA with VeDBA for fish with accelerometers implanted intraperitoneally.

ODBA and VeDBA were calculated by first removing the static component of acceleration (the acceleration due to gravity) from the acceleration timeseries using the method detailed by Shepard et al. (2008). Briefly, this involved identifying the optimal smoothing algorithm for a steadily swimming sea bass. Smoothing intervals are species specific (with the gait and tail beat frequency influencing the optimal smoothing algorithm). After testing a range of smoothing parameters, $2 \mathrm{~s}$ was appropriate for separating the static from the dynamic acceleration for the sea bass in this study. Data were then converted to absolute values to reflect the change in acceleration from 0 (irrespective of the values being negative or positive) before the vectorial sum (VeDBA) or the sum (ODBA) was calculated using the following equations:

$$
\begin{aligned}
\mathrm{VeDBA} & =\sqrt{A_{X}^{2}+A_{Y}^{2}+A_{Z}^{2}} \\
\mathrm{ODBA} & =A_{X}+A_{Y}+A_{Z}
\end{aligned}
$$

where $A_{X}, A_{Y}$ and $A_{Z}$ are the absolute dynamic acceleration values measured with respect to the $X, Y$ and $Z$ axes, respectively (cf. Qasem et al. 2012).

Mean VeDBA and ODBA were calculated every $2 \mathrm{~s}$ to incorporate the peak and trough of the fish tail beat prior to further processing. The measuring period for each $M_{\mathrm{O}_{2}}$ value was used to extract the mean VeDBA or ODBA value over the corresponding time.

It has been noted for some species (e.g. eels $A n-$ guilla anguilla; Methling et al. 2011) that tagging can affect the cost of transport (COT), a measure of the relative cost of motion at each speed, that can be used to estimate optimal swimming speed, i.e. the speed at which COT is a minimum (Schmidt-Nielsen 1972). To assess whether there was a difference in COT before and after logger implantation, the minimum cost of transport $\left(\mathrm{COT}_{\min }\right)$ and optimal swim- 
ming speed $\left(U_{\text {opt }}\right)$ were calculated and compared as a function of the ambient temperature, such that:

$$
\mathrm{COT}=\left(\frac{a}{U}\right)+b \times U^{(c-1)}
$$

where $a, b$ and $c$ are all constants and $U$ is the speed of the fish in body lengths per second. From the COT relationship $U_{\text {opt }}$ and the corresponding oxygen consumption at this speed, $\mathrm{COT}_{\text {min }}$ values were also determined.

The relationship between $M_{\mathrm{O}_{2}}$ and water speed and between $M_{\mathrm{O}_{2}}$ and acceleration was identified using a linear mixed model, with temperature, total length and sex as covariables and with the fish's identification number (ID) as a random factor. Models were compared and selected based on values of Akaike's information criterion (AIC) (Sakamoto et al. 1986).

The standard metabolic rate $\left(\mathrm{SMR}_{U}\right)$ was calculated by extrapolating the oxygen consumption value to zero water speed (Brett 1965, Dewar \& Graham 1994, Schurmann \& Steffensen 1997). To calculate the SMR for regressions between DBA and oxygen consumption, first, the DBA at zero water speed $\left(\mathrm{DBA}_{\mathrm{r}}\right)$ was calculated for each temperature group, yielding the resting DBA level (which includes minor adjustments in posture at rest). This $\mathrm{DBA}_{\mathrm{r}}$ value was then incorporated into the DBA/oxygen consumption regressions from the mixed effects model to calculate the $\mathrm{SMR}_{\mathrm{VeDBA}}$ and $\mathrm{SMR}_{\mathrm{ODBA}}$ values (for VeDBA and ODBA regressions, respectively).

These SMR values were then compared with previously published values for bass at different temperatures. SMRs were regressed against temperature using the following exponential relationship:

$$
\mathrm{SMR}=a \times e^{(b \times T)}
$$

where $a$ and $b$ are both constants and $T$ is the temperature in degrees Celsius.

Activity levels may be suppressed in the respirometer compared to the holding tank (Peake \& Farrell 2004), affecting the range of motion that we are able to attain in the study. To assess whether there was a difference in the activity level of fish in the holding tank and the respirometer, frequency distributions of DBA were compared by extracting the maximum and modal values of the frequency distributions in the 2 situations.

\section{Statistics}

Data were tested for normality using the Anderson Darling test for normality, and, if data were not nor- mally distributed, the values were log-transformed to satisfy requirements for subsequent statistical tests. Where appropriate, values are shown as means $( \pm \mathrm{SD})$, and the level of statistical significance was set at $\alpha=0.05$.

\section{RESULTS}

We have simultaneously measured dynamic body acceleration (both as ODBA and VeDBA) and oxygen consumption at rest and while swimming at a range of water speeds in 9 European sea bass Dicentrarchus labrax at ambient temperatures between 5.5 and $17.5^{\circ} \mathrm{C}$ (Table 1). However, during the 5 to 6 mo experiment, 3 fish (Fish 4,5 and 6) expelled their loggers, resulting in no data for summer temperatures $\left(13\right.$ and $\left.14^{\circ} \mathrm{C}\right)$ for these individuals.

Tests showed no detectable background bacterial respiration in the swim chamber; thus, no correction of oxygen consumption values was needed.

\section{Metabolic rates and activity level}

Oxygen consumption scaled exponentially with swimming speed at all temperatures (Fig. 2). For statistical comparison of $M_{\mathrm{O}_{2}}$ with $U, M_{\mathrm{O}_{2}}$ values were log-transformed. Water speed and temperature had significant positive effects on oxygen consumption (Table 2, Fig. 2).

The relationship between dynamic body acceleration and oxygen consumption was developed using a

Table 2. Dicentrarchus labrax. Significance of variables and variable interactions for water speed or dynamic body acceleration (VeDBA/ODBA: vectorial/overall dynamic body acceleration) and oxygen consumption $\left(M_{\mathrm{O}_{2}}\right)$ for 9 European sea bass. TL: total length

\begin{tabular}{|lcr|}
\hline Model & Variable & p-value \\
\hline $\boldsymbol{M}_{\mathrm{O}_{2}}$ \& water speed & Water speed & $<0.0001$ \\
& Temperature & $<0.0001$ \\
& TL & 0.3664 \\
$\boldsymbol{M}_{\mathrm{O}_{2}}$ \& VeDBA & Sex & 0.5727 \\
& VeDBA & $<0.0001$ \\
& Temperature & $<0.0001$ \\
& TL & 0.8277 \\
$\boldsymbol{M}_{\mathrm{O}_{2}}$ \& ODBA & Sex & 1.0000 \\
& ODBA & $<0.0001$ \\
& Temperature & $<0.0001$ \\
& TL & 0.6944 \\
& Sex & 1.0000 \\
\hline
\end{tabular}



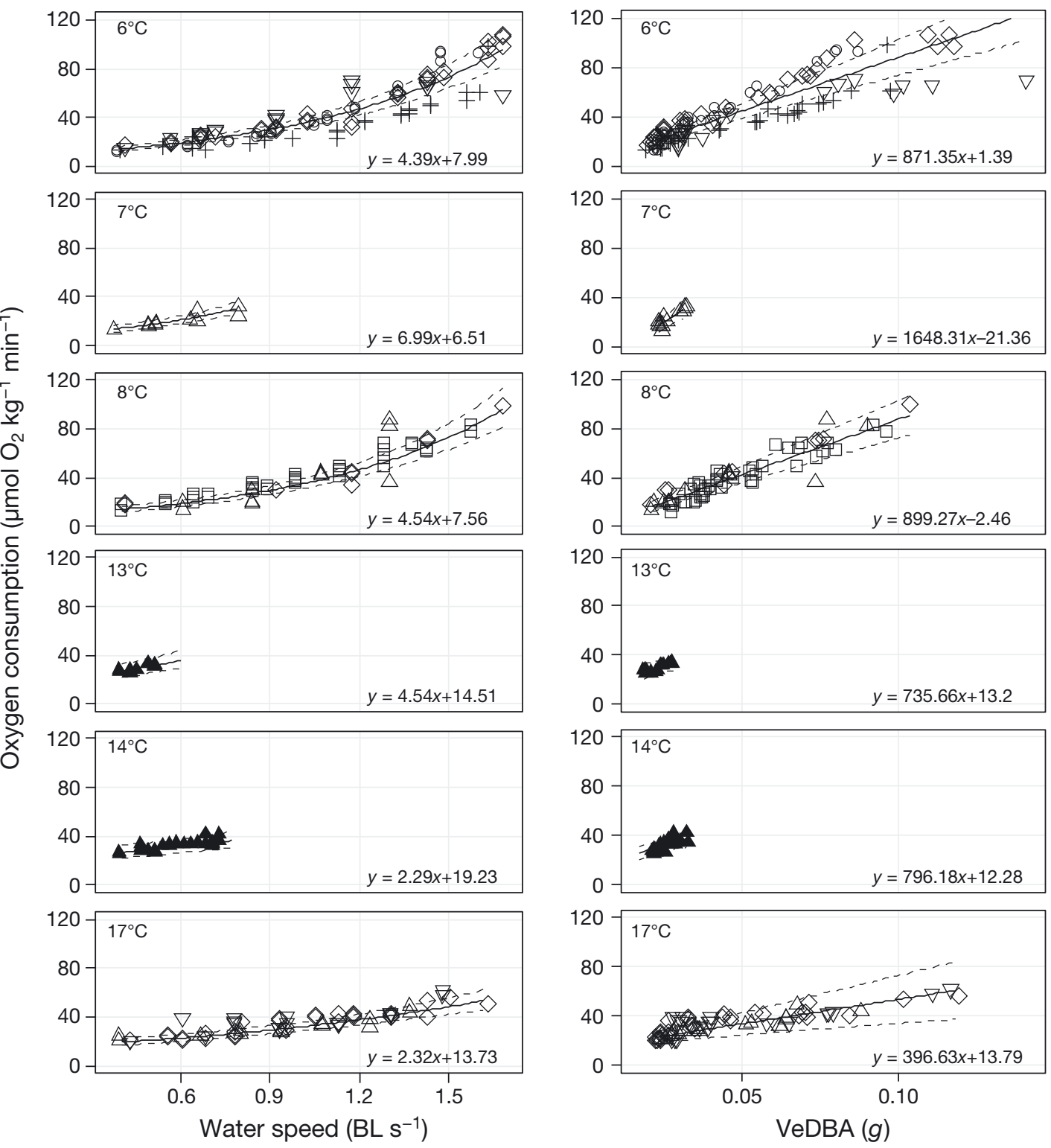

Fig. 2. Dicentrarchus labrax. Oxygen consumption $\left(M_{\mathrm{O}_{2}}\right)$ as a function of water speed $(U)$ and vectorial dynamic body acceleration (VeDBA) of European sea bass at a range of ambient temperatures (individuals are represented by different symbols). Data were fitted with a linear mixed effect model. Each line represents the relationship between $M_{\mathrm{O}_{2}}$ and water speed $\left(\log \left(M_{\mathrm{O}_{2}}\right)=U \times a+b\right)$ and $M_{\mathrm{O}_{2}}$ and VeDBA $\left(M_{\mathrm{O}_{2}}=\operatorname{VeDBA} \times a+b\right)$ at a given temperature. Dashed lines correspond to confidence intervals around these fits. See Table 2 for regression values and statistical comparisons. Note the low spread of values at 7,13 and $14^{\circ} \mathrm{C}$, which results from unsteady swimming of the sea bass at relatively low speeds (0.7 to 0.8 body lengths $[\mathrm{BL}] \mathrm{s}^{-1}$ )

mixed model, where temperature, total length and sex were used as predictor variables and fish ID was a random factor. Acceleration (ODBA/VeDBA) and temperature were the only significant $(\mathrm{p}<0.05)$ predictor variables with positive effects on oxygen consumption (Table 2, Fig. 2). Total length and sex were non-significant ( $p>0.05$; Table 2$)$.

There was no significant difference between VeDBA and ODBA $(p=0.995)$, though the AIC was lower for
VeDBA (2181) in comparison to ODBA (2191). VeDBA was therefore used as the dynamic body acceleration metric for further comparisons.

There was also an exponential relationship between VeDBA and water speed $\left(U, \mathrm{BL} \mathrm{s}^{-1}\right)$, the relationship being described by:

$$
\mathrm{VeDBA}=0.0109 \times \mathrm{e}^{(1.3911 \times U)}
$$

$\left(r^{2}=0.87, p<0.001\right)$ (Fig. 3). 


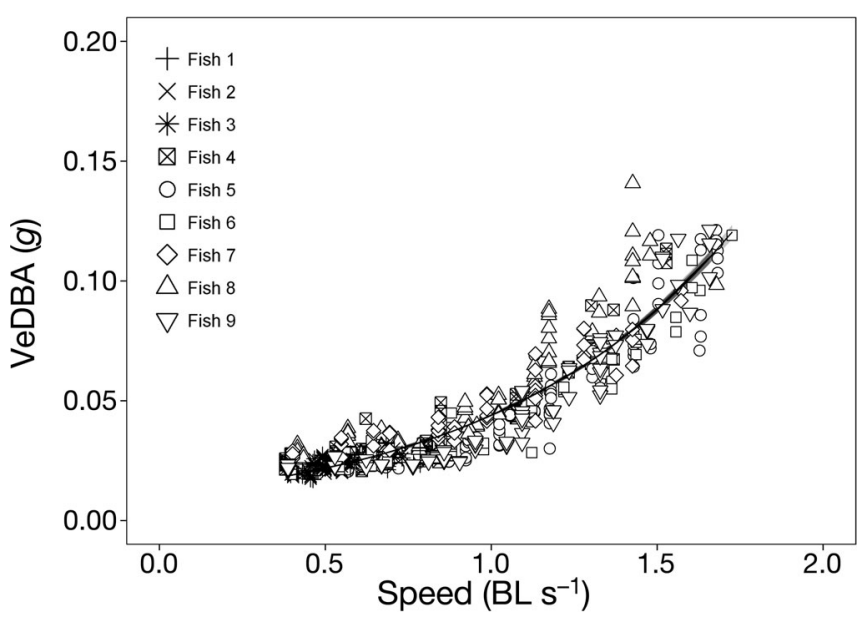

Fig. 3. Dicentrarchus labrax. Vectorial dynamic body acceleration (VeDBA) as a function of water speed $(U$, body lengths $[\mathrm{BL}] \mathrm{s}^{-1}$ ) for 9 European sea bass. The regression line corresponds to the exponential increase in VeDBA with water speed $\left(\right.$ VeDBA $\left.=0.0109 \times \mathrm{e}^{(1.3911 \times U)} ; \mathrm{r}^{2}=0.87, \mathrm{p}<0.001\right)$. Data were combined from all experiments in this comparison, as the fish speed and VeDBA are both independent of temperature

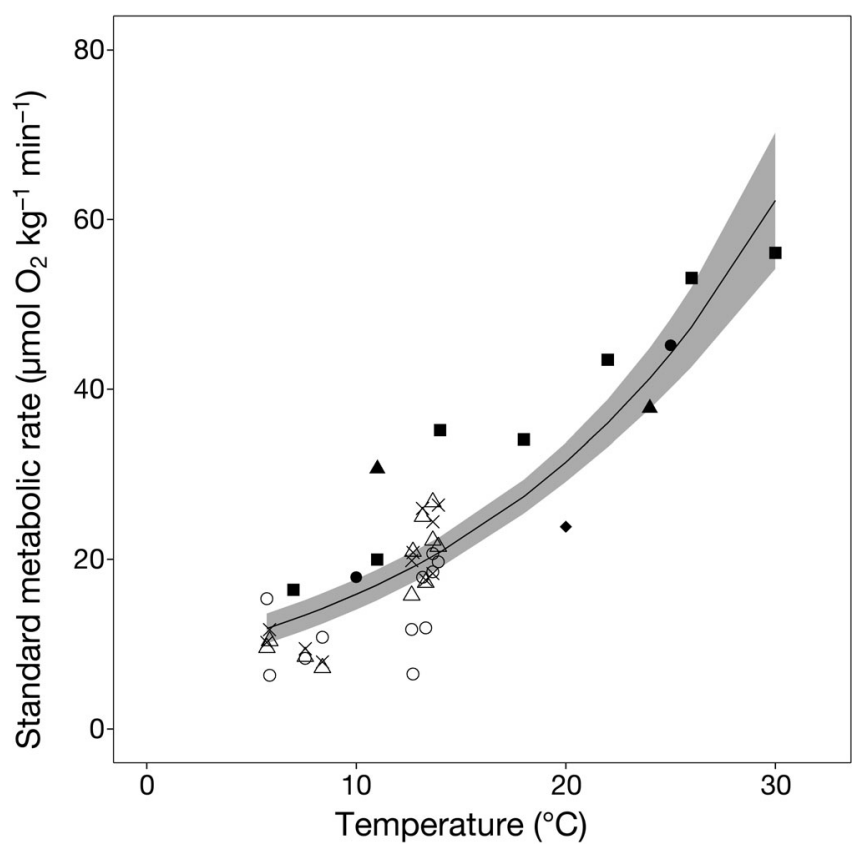

Fig. 4. Dicentrarchus labrax. Standard metabolic rate (SMR) as a function of water temperature for European sea bass. SMR values derived from models between oxygen consumption and $(O)$ vectorial and $(\Delta)$ overall dynamic body acceleration, and $(\mathbf{x})$ swimming speed, together with previously published values. @: Claireaux \& Lagarde (1999); 口: Claireaux et al. (2006); : Herskin \& Steffensen (1998); A: Sureau (1995). The shaded area corresponds to the $95 \%$ confidence limits of the exponential increase in SMR with temperature when all data were combined $(\mathrm{SMR}=7.86 \pm$ $\left.1.06 \times \mathrm{e}^{(0.069 \pm 0.006 \times T)} ; \mathrm{r}^{2}=0.82, \mathrm{p}<0.0001\right)$

\section{Standard metabolic rate}

Standard metabolic rate $\left(\mathrm{SMR}_{U}\right)$ was derived by extrapolating the oxygen consumption to zero swimming speed. These SMRs were regressed against ambient temperature and plotted together with those cited in several previously published studies using Eq. (5) (Fig. 4). SMRs derived from this study were lower than those previously published at similar temperatures (Fig. 4). Though there was a strong correlation between SMR and temperature when all values were combined (Eq. 7) in contrast to when only the previously published values were used (Eq. 8):

$$
\begin{aligned}
& \mathrm{SMR}=7.68 \pm 1.06 \times \mathrm{e}^{(0.069 \pm 0.006 \times \mathrm{T}} \\
& \left(\mathrm{p}<0.0001, \mathrm{r}^{2}=0.82\right) \\
& \mathrm{SMR}=13.83 \pm 2.56 \times \mathrm{e}^{(0.047 \pm 0.008 \times 7} \\
& \left(\mathrm{p}<0.001, \mathrm{r}^{2}=0.80\right)
\end{aligned}
$$

where $T$ is the temperature $\left({ }^{\circ} \mathrm{C}\right)$.

\section{Cost of transport before and after logger implantation}

$\mathrm{COT}_{\text {min }}$ values were higher before than after tagging (Fig. 5). For example, at $8^{\circ} \mathrm{C} \mathrm{COT}_{\text {min }}$ ranged from 74.5-102.4 $\mu \mathrm{mol} \mathrm{O}_{2} \mathrm{~kg}^{-1} \mathrm{BL}^{-1}$ before tagging to $62.7-77.7 \mu \mathrm{mol} \mathrm{O} \mathrm{kg}^{-1} \mathrm{BL}^{-1}$ after tagging. There was a significant linear relationship between temperature and $\mathrm{COT}_{\min }$ in post-tagging trials $\left(\mathrm{r}^{2}=\right.$ $0.79, \mathrm{p}<0.01$; Fig. 5). Despite this relationship between $\mathrm{COT}_{\min }$ and temperature, there was no significant relationship between $U_{\text {opt }}$ and temperature $\left(\mathrm{r}^{2}=0.51, \mathrm{p}=0.11\right)$.

\section{DBA in the respirometer and holding tank}

To assess whether there was a difference in the activity level of fish in the holding tank and in the swim chamber, frequency distributions of VeDBA in these 2 situations were compared (Fig. 6). Activity levels (VeDBA) were consistently higher in the holding tank compared to the swim chamber, with higher modes and maximum levels (Table 3). Whilst in the swim chamber, fish swam progressively faster up to the maximum sustained speed; as the water speed increased, the spectrum of VeDBA values also increased encompassing the range of activity in the holding tank (Fig. 6c). 


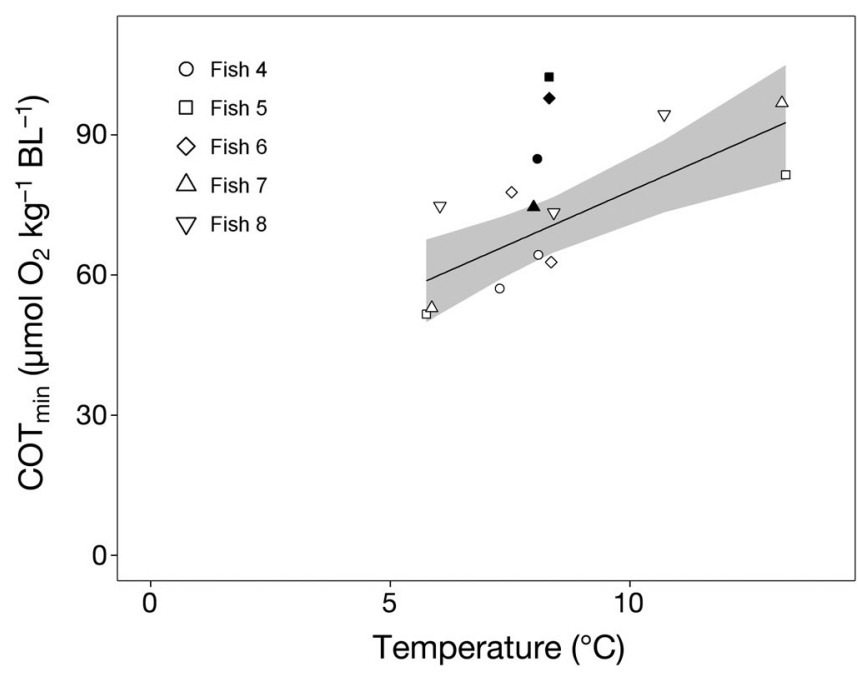

Fig. 5. Dicentrarchus labrax. Minimum cost of transport $\left(\mathrm{COT}_{\min }\right)$ as a function of ambient temperature for individual European sea bass prior to logger implantation (black symbols) and after (white symbols). Individuals are represented by symbols. The solid line corresponds to the linear regression between temperature and $\mathrm{COT}_{\min }$ after tagging $\left(\mathrm{COT}_{\min }\right.$ $\left.=32.72+T \times 4.52 ; \mathrm{r}^{2}=0.79, \mathrm{p}=0.004\right)$. The shaded area represents the $95 \%$ confidence limits of the regression line
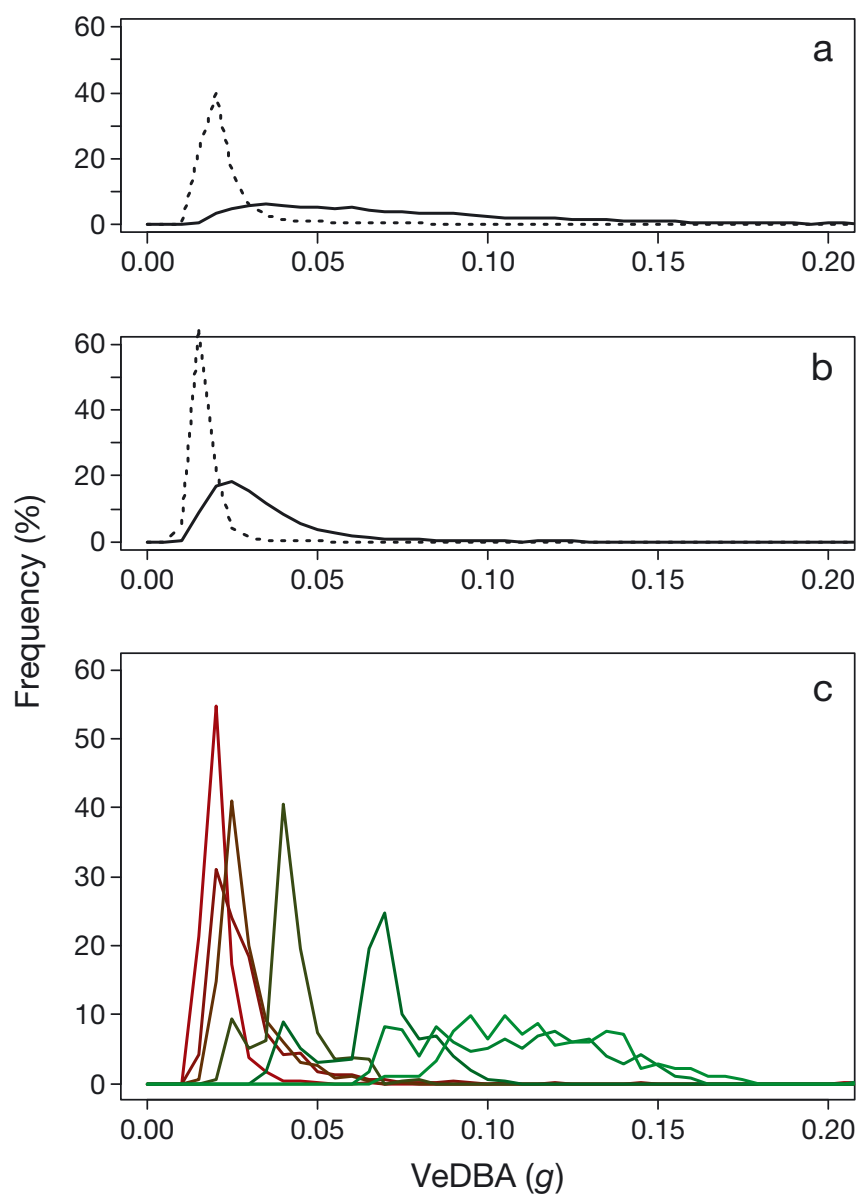

Table 3. Dicentrarchus labrax. Statistics from frequency distributions of vectorial dynamic body acceleration for European sea bass in a swim chamber and holding tank

\begin{tabular}{|lccc|}
\hline \multirow{2}{*}{ Statistic } & Fish & \multicolumn{2}{c|}{ Location } \\
\cline { 3 - 4 } & & Swim chamber & Holding tank \\
\hline Mode & 1 & 0.0186 & 0.0349 \\
& 2 & 0.0261 & 0.0523 \\
Max. & 1 & 0.0854 & 0.0935 \\
& 2 & 0.663 & 1.1590 \\
\hline
\end{tabular}

\section{DISCUSSION}

Our results indicate that there is a significant correlation between dynamic body acceleration (measured here as ODBA and VeDBA) and activity-specific energy expenditure in sea bass Dicentrarchus labrax. Both oxygen consumption and dynamic body acceleration increased with water speed at all temperatures (Fig. 2). The exponential relationship between swim speed and oxygen consumption found in the present study is broadly similar to those previously reported for other teleost fish (Farrell 2007, Melzner et al. 2009) including European sea bass (Claireaux \& Lagarde 1999, Claireaux et al. 2006). Our general finding that DBA scales linearly with oxygen consumption also confirms previous results from both terrestrial and aquatic species (Gleiss et al. 2009, Halsey \& White 2010, Wilson et al. 2013).

\section{Effects of tagging and cost of transport}

Recent studies have shown that fish carrying externally attached devices incur increases in the energetic cost of swimming at optimal speeds (Methling et al. 2011). The data loggers used in the present study were implanted internally into the peritoneum, to reduce the effect of logger drag. Nonetheless we wanted to establish that internal implantation minimised any impact on swimming performance and energy use. For this we compared the cost of transport for the steadily swimming sea bass before and after tagging. Our results indicate that the $\mathrm{COT}_{\text {min }}$ was consistently lower after tagging

Fig. 6. Dicentrarchus labrax. $(\mathrm{a}, \mathrm{b})$ Frequency distribution of vectorial dynamic body acceleration (VeDBA, g) whilst in the swim chamber (dotted line) and holding tank (solid line) for European sea bass (a) Fish 1 and (b) Fish 2. (c) Frequency distribution of VeDBA whilst swimming at a range of set speeds for Fish 2 in the respirometer (from 0.3 to 1.6 body lengths $\mathrm{s}^{-1}$, red to green, respectively) 
(Fig. 5). The unexpected higher COT prior to tagging may reflect increased oxygen consumption due to stress induced by the new and unfamiliar surroundings in the swim chamber (Martins et al. 2011). This analysis therefore does not fully establish that the fish were unaffected by tagging, but rather suggests that the fish became accustomed to the experimental apparatus over time and were therefore less stressed in post-tagging trials than in pre-tagged trials, with a consequent reduction in oxygen consumption. Nonetheless, these results do indicate that tagging per se did not lead to any increase in the energetic costs of swimming. Posttagging $\mathrm{COT}_{\min }$ also increased exponentially with temperature, a relationship also reported for other fish species, including chub mackerel Scomber japonicus (Dickson et al. 2002). Therefore, we conclude that, for sea bass at least, it is difficult to assess the effect of tagging using pre- and posttagging trials on the same individuals because stress, and therefore oxygen consumption, may be reduced over time as the fish become accustomed to the experimental apparatus, despite our efforts to acclimatise the bass in this study to being handled by presenting them with 'net challenges' each day.

\section{Differences between VeDBA and ODBA}

Dynamic body acceleration can be calculated by either deriving the sum (ODBA) or the vectorial sum (VeDBA) of the acceleration. ODBA has previously been shown to be a better proxy for oxygen consumption in a range of species, including humans (Qasem et al. 2012). However, as the accelerometer is not necessarily aligned precisely with respect to the vertical, VeDBA may be a better proxy in the current application. The accelerometer was implanted in the peritoneal cavity of the bass, standardising the position of the device between individuals after the initial recovery period (during which time the logger becomes encapsulated in connective tissue). We have therefore compared the fits of both VeDBA and ODBA with oxygen consumption to assess which DBA metric provided the best fit. There was no significant difference between the mixed models for ODBA or VeDBA, mirroring results from a recent study (Qasem et al. 2012), although the model with VeDBA had a lower AIC than ODBA; suggesting that VeDBA is a better proxy for oxygen consumption than ODBA. This finding is similar to those of Qasem et al. (2012) who predicted that this should be the case in situations where a consistent orientation of the data logger cannot be guaranteed between individuals.

\section{Standard metabolic rate}

Our values of SMR (i.e. the oxygen consumption when the fish is at rest) derived by extracting the oxygen consumption at zero swimming speed $\left(\mathrm{SMR}_{U}\right)$ or minimum activity level (SMR $\mathrm{VeDBA}_{\mathrm{V}}$ and $\left.\mathrm{SMR}_{\mathrm{ODBA}}\right)$ are somewhat lower than those reported previously for sea bass (Herskin \& Steffensen 1998, Claireaux \& Lagarde 1999, Claireaux et al. 2006) (Fig. 4). Though, there is a strong correlation $\left(\mathrm{r}^{2}\right)$ between SMR and temperature when all results are combined (Eq. 7).

In the present study we estimated the SMR of bass $(800 \mathrm{~g})$ at $13^{\circ} \mathrm{C}$ to be between 16.45 and $19.89 \mu \mathrm{mol}$ $\mathrm{kg}^{-1} \mathrm{~min}^{-1}$ as derived from water speed and VeDBA regressions, respectively. After correcting for massspecific differences, the equivalent SMR calculated from previous studies of sea bass would be $25.48 \mu \mathrm{mol}$ $\mathrm{kg}^{-1} \min ^{-1}$ (Eq. 8). Differences may be due to the higher mean temperature in the other studies (18.17 \pm $\left.7.46^{\circ} \mathrm{C}\right)$, in contrast to the present study $(10.83 \pm$ $4.45^{\circ} \mathrm{C}$ ). Other factors which may have resulted in the observed differences include handling stress or population differences of genetically distinct stocks. Although all fish in both the present and cited studies were obtained from hatcheries (Herskin \& Steffensen 1998, Claireaux \& Lagarde 1999, Claireaux et al. 2006), genetic differences between populations may affect metabolic rates (Gamperl et al. 2009). Alternatively, the differences may simply reflect errors in deriving SMR by extrapolating from regressions where the closest data points are still some way from the intercept. This is particularly germane in studies seeking to describe SMR rather than resting metabolic rate (RMR) (Carlson et al. 2004). RMR is the metabolic rate of an animal at rest, whilst the SMR is the minimum metabolic rate required to sustain life. In contrast to the RMR, the SMR can be extrapolated from an active animal, and therefore can be over/underestimated if there are inaccuracies in the regression slope of the active animal.

\section{The problem with swim tunnels}

Swim tunnel studies have frequently been used to shed light on relationships between swimming speed (or performance) and metabolism in fish (Claireaux \& Lagarde 1999, Steinhausen et al. 2010, Gleiss et al. 2010). However, many authors question the validity 
of the capacity of swim tunnel work to replicate natural swimming conditions (Nelson et al. 2002). Novel environments may cause the fish to behave abnormally for prolonged periods, resulting in an increased oxygen uptake (Wendelaar Bonga 1997), and issues may arise due to the size or design of the swim tunnel (Tang \& Boisclair 1993), with animal movement potentially limited at crucial times such as during gait transition (Peake \& Farrell 2004). In the present study, the limited space in the swim chamber compared to the holding tank had an immediately quantifiable effect on the activity level (DBA profile) of the fish (Fig. 6). Nonetheless, the range of activity levels achieved during the swim trials (water speeds of between 0.3 and 1.6 $\mathrm{BL} \mathrm{s}^{-1}$ ) successfully spanned the range of activity exhibited by the fish in the holding tank (Fig. 6). However, it must be noted that, the forced steady swimming used during respirometry trials is not always representative of the behaviour that fish exhibit in unimpeded (free-swimming) scenarios, and may result in erroneous oxygen consumption measures.

\section{Loggers versus transmitters}

Loggers and transmitters can be used to record the acceleration of animals both in the field and laboratory. Acceleration in this study was recorded using a logger, which provides continuously sampled acceleration at a fine resolution. Other recent studies have shown the value of using acceleration transmitters to track fish (Wilson et al. 2013), which combine and transmit acceleration every few seconds.

There are both benefits and caveats when using acoustically transmitted and logged acceleration. Both acoustically transmitted and logged acceleration provide an 'overall' activity level (DBA) indicator, which can be used to calculate activity-specific energy use (Gleiss et al. 2010, Wilson et al. 2013). However, logged acceleration can also be used to extract more detailed information about the behaviour of the animal (Whitney et al. 2007, 2010, Broell et al. 2013, Brownscombe et al. 2013), for example as a means to identify specific behavioural events including feeding (Broell et al. 2013, Gleiss et al. 2013). We are unable to extract these behaviours using transmitters, though loggers are not always practical or feasible to use as they must be retrieved at the end of the study. Researchers therefore need to select the appropriate recording or transmitting device depending on their research aims and the likelihood that devices will be easily retrieved at the end of the study.

\section{CONCLUSIONS}

Electronic data loggers (data storage tags) have previously been shown to provide unparalleled insights into the vertical movement and habitat selection of aquatic animals in the wild (Sims et al. 2005, Metcalfe et al. 2008, Righton et al. 2010). Now, with the incorporation of tri-axial accelerometers, these devices promise to provide a repeatable and robust method for estimating activity-specific metabolic rates. The correlations between DBA and $M_{\mathrm{O}_{2}}$ demonstrate that DBA can be used as a metric to estimate activity-specific metabolic rates in fish (Wilson et al. 2006, 2013, Gleiss et al. 2010), and reconfirms the use of acceleration as a proxy for activity-specific metabolic rates in the field (Halsey et al. 2011).

Acceleration data loggers can be implanted internally into fish and can, with an appropriate duty cycle, have a long-operating life. This suggests that DBA could be a useful proxy for estimating activityspecific energy expenditure from fish in mesocosm or field studies over extended periods where other methods (e.g. oxygen consumption) would be more problematic, although details of the physiological inter-relationships between temperature, specific dynamic action, basal, standard and active metabolic rates would need to be derived from laboratory studies before DBA could be used to provide a complete estimate for field metabolic rate. Nonetheless, DBA would appear to be a valuable tool to gain a clearer picture of how fish make energy-based tradeoffs between different levels of activity when faced with confliction or competing demands arising from increased and combined environmental stressors.

An additional potential application of accelerometers in relation to activity-specific energy expenditure is the capability of this technology to record very short periods of intense activity, which, for most fish, is supported by anaerobic metabolism. White muscle (the bulk of the muscle in most fish) has a poor blood supply, and white muscle activity relies largely on anaerobic metabolism. White muscle, therefore, functions largely as an 'emergency power pack' during burst swimming that is often essential for predator avoidance or prey capture; behaviours that, particularly in the case of predator avoidance, can be critical to survival. However, most laboratory-based studies on metabolic processes in fish can only be carried out when the animal is in a steady-state, either resting or swimming, and metabolising aerobically. This is because the experimental methods used are unable to capture sufficient physiological information during brief episodes of intense activity. Consequently, it 
has previously been difficult to investigate how such life-critical anaerobic capabilities are affected by temperature and other stressors (e.g. hypoxia, acidification, starvation).

Accelerometry, therefore, offers, for the first time, the potential to investigate the effects of environmental temperature and other environmental stressors (alone and in combination) on both the aerobic and anaerobic capabilities of fish. Furthermore, this technology can be readily applied in both laboratory (for ground-truthing) and field situations; therefore offering a unique capability for understanding how environmental stressors affect fish energetics, particularly their life-critical, anaerobic capacities, in their natural environment and how they make tradeoffs between different activities that allow them to cope with environmental stress.

Acknowledgements. We thank Lewis Halsey and Adrian Gleiss for helpful advice and comments on data analysis, and we thank Matthew Eade for his support with fish husbandry. S.W. was funded by a postgraduate scholarship from the Fisheries Society of the British Isles. Experiments were supported by a Seedcorn grant from the Centre for Environment Fisheries and Aquaculture (DP268). We are grateful for the comments of 3 anonymous referees, which greatly improved the manuscript.

\section{LITERATURE CITED}

Axelsson M, Altimiras J, Claireaux G (2002) Post-prandial blood flow to the gastrointestinal tract is not compromised during hypoxia in the sea bass Dicentrarchus labrax. J Exp Biol 205:2891-2896

> Beamish FWH, Trippel EA (1990) Heat increment: A static or dynamic dimension in bioenergetic models? Trans Am Fish Soc 119:649-661

Béguer-Pon M, Benchetrit J, Castonguay M, Aarestrup K, Campana SE, Stokesbury MJW, Dodson JJ (2012) Shark predation on migrating adult American eels (Anguilla rostrata) in the Gulf of St. Lawrence. PLoS ONE 7:e46830

Bell WH, Terhune LDB (1970) Water tunnel design for fisheries research. Fish Res Board Can Tech Rep 195: p 1-69

Bennett AF, Nagy K (1977) Energy expenditure in freeranging lizards. Ecology 58:697-700

Bestley S, Patterson T, Hindell M, Gunn JS (2008) Feeding ecology of wild migratory tunas revealed by archival tag records of visceral warming. J Anim Ecol 77:1223-1233

Brett JR (1965) The relationship of size to rate of oxygen consumption and sustained swimming speed of sockeye salmon (Oncorhynchus nerka). J Fish Res Board Can 22: 1491-1501

Broell F, Noda T, Wright S, Domenici P, Steffensen JF, Auclair JP, Taggart CT (2013) Accelerometer tags: detecting and identifying activities in fish and the effect of sampling frequency. J Exp Biol 216:1255-1264

Brown JH, Gillooly JF, Allen AP, Savage VM, West GB (2004) Toward a metabolic theory of ecology. Ecology 85: 1771-1789
Brownscombe JW, Thiem JD, Hatry C, Cull F, Haak CR, Danylchuk AJ, Cooke SJ (2013) Recovery bags reduce post-release impairments in locomotory activity and behaviour of bonefish (Albula spp.) following exposure to angling-related stressors. J Exp Mar Biol Ecol 440: 207-215

Butler PJ, Green JA, Boyd IL, Speakman JR (2004) Measuring metabolic rate in the field: the pros and cons of the doubly labelled water and heart rate methods. Funct Ecol 18:168-183

Carlson JK, Goldman KJ, Lowe CG (2004) Metabolism, energetic demand, and endothermy. In: Carrier JC, Musick JA, Heithaus MR (eds) Biology of sharks and their relatives. CRC Press, Boca Raton, FL, p 203-224

Casselman MT, Anttila K, Farrell AP (2012) Using maximum heart rate as a rapid screening tool to determine optimum temperature for aerobic scope in Pacific salmon Oncorhynchus spp. J Fish Biol 80:358-377

Claireaux GE, Lagarde J (1999) Influence of temperature, oxygen and salinity on the metabolism of the European sea bass. J Sea Res 42:157-168

> Claireaux G, Couturier C, Groison A (2006) Effect of temperature on maximum swimming speed and cost of transport in juvenile European sea bass (Dicentrarchus labrax). J Exp Biol 209:3420-3428

> Clark TD, Ryan T, Ingram BA, Woakes AJ, Butler PJ, Frappell PB (2005) Factorial aerobic scope is independent of temperature and primarily modulated by heart rate in exercising Murray cod (Maccullochella peelii peelii). Physiol Biochem Zool 78:347-355

Clark TD, Sandblom E, Hinch SG, Patterson DA, Frappell PB, Farrell AP (2010) Simultaneous biologging of heart rate and acceleration, and their relationships with energy expenditure in free-swimming sockeye salmon (Oncorhynchus nerka). J Comp Physiol B 180:673-684

Clarke A, Johnston NM (1999) Scaling of metabolic rate with body mass and temperature in teleost fish. J Anim Ecol 68:893-905

Cooke SJ, Thorstad EB, Hinch SG (2004) Activity and energetics of free-swimming fish: insights from electromyogram telemetry. Fish Fish 5:21-52

> Dewar H, Graham JB (1994) Studies of tropical tuna swimming performance in a large water tunnel. 1. Energetics. J Exp Biol 192:13-31

> Dickson KA, Donley JM, Sepulveda C, Bhoopat L (2002) Effects of temperature on sustained swimming performance and swimming kinematics of the chub mackerel Scomber japonicus. J Exp Biol 205:969-980

Dupont-Prinet A, Claireaux G, McKenzie DJ (2009) Effects of feeding and hypoxia on cardiac performance and gastrointestinal blood flow during critical speed swimming in the sea bass Dicentrarchus labrax. Comp Biochem Physiol A Mol Integr Physiol 154:233-240

Edwards RRC, Finlayson DM, Steele JH (1972) An experimental study of the oxygen consumption, growth, and metabolism of the cod (Gadus morhua). J Exp Biol 8: 299-309

> Farrell AP (2007) Cardiorespiratory performance during prolonged swimming tests with salmonids: a perspective on temperature effects and potential analytical pitfalls. Philos Trans R Soc Lond B Biol Sci 362:2017-2030

> Fitzgibbon QP, Seymour RS, Ellis D, Buchanan J (2007) The energetic consequence of specific dynamic action in southern bluefin tuna Thunnus maccoyii. J Exp Biol 210: 290-298 
Fonds M, Cronie R, Vethaak AD, Van der Puyl P (1992) Metabolism, food consumption and growth of plaice (Pleuronectes platessa) and flounder (Platichthys flesus) in relation to fish size and temperature. Neth J Sea Res 29:127-143

Frappell PB, Butler PJ (2004) Minimal metabolic rate, what it is, its usefulness, and its relationship to the evolution of endothermy: a brief synopsis. Physiol Biochem Zool 77: 865-868

Fry FEJ (1971) The effect of environmental factors on the physiology of fish. In: Hoar WS, Randall DJ (eds) Fish physiology. VI. Academic Press, New York, NY, p 1-98

> Gamperl AK, Busby CD, Hori TS, Afonso LOB, Hall JR (2009) Hemoglobin genotype has minimal influence on the physiological response of juvenile Atlantic cod (Gadus morhua). Physiol Biochem Zool 82:483-494

Gilman MB, Wells CL (1993) The use of heart rates to monitor exercise intensity in relation to metabolic variables. Int J Sports Med 14:339-344

> Gleiss AC, Norman B, Liebsch N, Francis C, Wilson RP (2009) A new prospect for tagging large free-swimming sharks with motion-sensitive data-loggers. Fish Res 97: 11-16

Gleiss AC, Dale JJ, Holland KN, Wilson RP (2010) Accelerating estimates of activity-specific metabolic rate in fishes: testing the applicability of acceleration data-loggers. J Exp Mar Biol Ecol 385:85-91

Gleiss AC, Wright S, Liebsch N, Wilson RP, Norman B (2013) Contrasting diel patterns in vertical movement and locomotor activity of whale sharks at Ningaloo Reef. Mar Biol 160:2981-2992

Griffiths JS, Alderdice DF (1972) Effects of acclimation and acute temperature experience on swimming speed. J Fish Res Board Can 29:251-264

Grøttum J, Sigholt T (1998) A model for oxygen consumption of Atlantic salmon (Salmo salar) based on measurements of individual fish in a tunnel respirometer. Aquacult Eng $17: 241-251$

Halsey LG, White CR (2010) Measuring energetics and behaviour using accelerometry in cane toads Bufo marinus. PLoS ONE 5:e10170

Halsey LG, Shepard ELC, Wilson RP (2011) Assessing the development and application of the accelerometry technique for estimating energy expenditure. Comp Biochem Physiol A Mol Integr Physiol 158:305-314

> Herskin J, Steffensen JF (1998) Energy savings in sea bass swimming in a school: measurements of tail beat frequency and oxygen. J Fish Biol 53:366-376

Hinch SG, Rand PS (1998) Swim speeds and energy use of upriver-migrating sockeye salmon (Oncorhynchus nerka): role of local environment and fish characteristics. Can J Fish Aquat Sci 1831:1821-1831

> Iversen NK, Dupont-Prinet A, Findorf I, McKenzie DJ, Wang $\mathrm{T}$ (2010) Autonomic regulation of the heart during digestion and aerobic swimming in the European sea bass (Dicentrarchus labrax). Comp Biochem Physiol A Mol Integr Physiol 156:463-468

> Jordan AD, Steffensen JF (2007) Effects of ration size and hypoxia on specific dynamic action in the cod. Physiol Biochem Zool 80:178-185

> Lee CG, Farrell AP, Lotto A, Hinch SG, Healey MC (2003) Excess post-exercise oxygen consumption in adult sockeye (Oncorhynchus nerka) and coho (O. kisutch) salmon following critical speed swimming. J Exp Biol 206: 3239-3251
Lefrançois C, Odion M, Claireaux G (2001) An experimental and theoretical analysis of the effect of added weight on the energetics and hydrostatic function of the swimbladder of European sea bass (Dicentrarchus labrax). Mar Biol 139:13-17

Martins CIM, Castanheira MF, Engrola S, Costas B, Conceição LEC (2011) Individual differences in metabolism predict coping styles in fish. Appl Anim Behav Sci 130: 135-143

Masman D, Daan S, Beldhuis HJA (1988) Ecological energetics of the kestrel: daily energy expenditure throughout the year based on time-energy budget, food intake and doubly labeled water methods. Ardea 76:64-81

McCue MD (2006) Specific dynamic action: a century of investigation. Comp Biochem Physiol A Mol Integr Physiol 144:381-394

Melzner F, Göbel S, Langenbuch M, Gutowska MA, Pörtner $\mathrm{H}$, Lucassen M (2009) Swimming performance in Atlantic cod (Gadus morhua) following long-term (4-12 months) acclimation to elevated seawater $\mathrm{PCO}_{2}$. Aquat Toxicol 92:30-37

Metcalfe JD, Righton DA, Hunter E, Eastwood P (2008) Migration and habitat choice in marine fish. In: Magnhagen C, Braithwaite VA, Forsgren E, Kapoor BG (eds) Fish behaviour. Science Publishers, Enfield, NH, p 187-233

> Methling C, Tudorache C, Skov PV, Steffensen JF (2011) Pop up satellite tags impair swimming performance and energetics of the European eel (Anguilla anguilla). PLoS ONE 6:e20797

> Moore A, Russell IC, Potter EC (1990) The effects of intraperitoneally implanted dummy acoustic transmitters on the behaviour and physiology of juvenile Atlantic salmon, Salmo salar L. J Fish Biol 37:713-721

Mullers R, Navarro R, Daan S, Tinbergen J, Meijer H (2009) Energetic costs of foraging in breeding Cape gannets Morus capensis. Mar Ecol Prog Ser 393:161-171

> Murchie KJ, Cooke SJ, Danylchuk AJ, Suski CD (2011) Estimates of field activity and metabolic rates of bonefish (Albula vulpes) in coastal marine habitats using acoustic tri-axial accelerometer transmitters and intermittentflow respirometry. J Exp Mar Biol Ecol 396:147-155

> Murphy H, Jenkins G, Hamer P, Swearer S (2011) Diel vertical migration related to foraging success in snapper Chrysophrys auratus larvae. Mar Ecol Prog Ser 433: 185-194

Nagy KA (2005) Field metabolic rate and body size. J Exp Biol 208:1621-1625

Nelson JA, Gotwalt PS, Reidy SP, Webber DM (2002) Beyond $U_{\text {crit }}$ : matching swimming performance tests to the physiological ecology of the animal, including a new fish 'drag strip'. Comp Biochem Physiol A Mol Integr Physiol 133:289-302

Ohlberger J, Staaks G, Hölker F (2007) Effects of temperature, swimming speed and body mass on standard and active metabolic rate in vendace (Coregonus albula). J Comp Physiol B 177:905-916

Page AJ, Cooper CE, Withers PC (2011) Effects of experiment start time and duration on measurement of standard physiological variables. J Comp Physiol B 181: $657-665$

Pakkasmaa S, Penttinen OP, Piironen J (2006) Metabolic rate of Arctic charr eggs depends on their parentage. J Comp Physiol B 176:387-391

> Peake SJ, Farrell AP (2004) Locomotory behaviour and post- 
exercise physiology in relation to swimming speed, gait transition and metabolism in free-swimming smallmouth bass (Micropterus dolomieu). J Exp Biol 207:1563-1575

Penttinen OP, Kukkonen JVK (2006) Body residues as dose for sublethal responses in alevins of landlocked salmon (Salmo salar m. sebago): a direct calorimetry study. Environ Toxicol Chem 25:1088-1093

Powell MD, Speare DJ, Daley J, Lovy J (2005) Differences in metabolic response to Loma salmonae infection in juvenile rainbow trout Oncorhynchus mykiss and brook trout Salvelinus fontinalis. Dis Aquat Org 67:233-237

Qasem L, Cardew A, Wilson A, Griffiths I and others (2012) Tri-axial dynamic acceleration as a proxy for animal energy expenditure; Should we be summing values or calculating the vector? PLoS ONE 7:e31187

Righton DA, Andersen KH, Neat F, Thorsteinsson V and others (2010) Thermal niche of Atlantic cod Gadus morhua: limits, tolerance and optima. Mar Ecol Prog Ser 420:1-13

Sakamoto Y, Ishiguro M, Kitagawa G (1986) Akaike information criterion statistics. D Reidel Publishing Company, Dordrecht

Schmidt-Nielsen K (1972) Locomotion: energy cost of swimming, flying, and running. Science 177:222-228

Schurmann H, Steffensen JF (1997) Effects of temperature, hypoxia and activity on the metabolism of juvenile Atlantic cod. J Fish Biol 50:1166-1180

Shaffer SA (2011) A review of seabird energetics using the doubly labeled water method. Comp Biochem Physiol A Mol Integr Physiol 158:315-322

Shaffer SA, Costa DP, Weimerskirch H (2001) Behavioural factors affecting foraging effort of breeding wandering albatrosses. J Anim Ecol 70:864-874

Shepard ELC, Wilson RP, Halsey LG, Quintana F and others (2008) Derivation of body motion via appropriate smoothing of acceleration data. Aquat Biol 4:235-241

Shepard ELC, Wilson RP, Quintana F, Laich AG, Forman DW (2009) Pushed for time or saving on fuel: fine-scale energy budgets shed light on currencies in a diving bird. Proc R Soc Lond B Biol Sci 276:3149-3155

Sims DW, Southall EJ, Tarling GA, Metcalfe JD (2005) Habitat-specific normal and reverse diel vertical migration in the plankton-feeding basking shark. J Anim Ecol 74: 755-761

Sloman KA, Wood CM, Scott GR, Wood S and others (2006) Tribute to R. G. Boutilier: the effect of size on the physiological and behavioural responses of oscar, Astronotus ocellatus, to hypoxia. J Exp Biol 209:1197-1205

Speakman JR (1997) Doubly labelled water: theory and practice. Chapman \& Hall, London

Speakman JR (1998) The history and theory of the doubly labeled water technique. Am J Clin Nutr 68:932S-938S

Steinhausen MF, Steffensen JF, Andersen NG (2010) The effects of swimming pattern on the energy use of gilthead seabream (Sparus aurata L.). Mar Freshw Behav Physiol 43:227-241

Stuart-Smith RD, White RWG, Barmuta LA (2007) A shift in the habitat use pattern of a lentic galaxiid fish: an acute behavioural response to an introduced predator. Environ Biol Fishes 82:93-100

Sureau D (1995) Télémétrie en milieu maritime, analyse du rythme cardiaque comme indicateur de la relation entre le poisson et son environnement naturel. Etude chez la sole (Solea solea) et le bar (Dicentrarchus labrax). PhD dissertation, University of Poitiers, Poitiers, France

Tang M, Boisclair D (1993) Influence of the size of enclosures on the swimming characteristics of juvenile brook trout (Salvelinus fontina). Can J Fish Aquat Sci 50: 1786-1793

> Thorarensen H, Gallaugher AP, Farrell AP (2005) The limitations of heart rate as a predictor of metabolic rate in fish. J Fish Biol 49:226-236

Walsberg GE, Hoffman TCM (2005) Direct calorimetry reveals large errors in respirometric estimates of energy expenditure. J Exp Biol 208:1035-1043

Wendelaar Bonga SE (1997) The stress response in fish. Physiol Rev 77:591-625

Whitney NM, Papastamatiou YP, Holland KN, Lowe CG (2007) Use of an acceleration data logger to measure diel activity patterns in captive whitetip reef sharks, Triaenodon obesus. Aquat Living Resour 20:299-305

> Whitney NM, Pratt HL, Pratt TC, Carrier JC (2010) Identifying shark mating behaviour using three-dimensional acceleration loggers. Endang Species Res 10:71-82

> Wilson RP, White CR, Quintana F, Halsey LG, Liebsch N, Martin GR, Butler PJ (2006) Moving towards acceleration for estimates of activity-specific metabolic rate in freeliving animals: the case of the cormorant. J Anim Ecol 75: 1081-1090

> Wilson SM, Hinch SG, Eliason EJ, Farrell AP, Cooke SJ (2013) Calibrating acoustic acceleration transmitters for estimating energy use by wild adult Pacific salmon. Comp Biochem Physiol A Mol Integr Physiol 164:491-498

Proofs received from author(s): October 16, 2013 